\title{
POWER QUALITY IN HIGH-TECH CAMPUS: AN EXEMPLARY CASE STUDY
}

\author{
Antonio MORENO-MUÑOZ ${ }^{1}$, Víctor PALLARES ${ }^{1}$, Matias LIÑAN ${ }^{1}$ \& Juan J. GONZALEZ ${ }^{2}$ \\ ${ }^{1}$ Universidad de Córdoba. \\ Área de Electrónica. Departamento de Electrotecnia y Electrónica. \\ Escuela Politécnica Superior. \\ Campus de Rabanales. Edificio A. Einstein. C-2 E-14071 Córdoba. SPAIN. \\ Tel: +35-57-218373. fax: +35-57-218316. e-mail: amoreno@uco.es \\ ${ }^{2}$ Universidad de Cádiz. \\ Área de Electrónica. Dpto. ISA, TE y Electrónica \\ Escuela Politécnica Superior \\ Avda. Ramón Puyol, s/n \\ E-11202-Algeciras-Cádiz. SPAIN.
}

\begin{abstract}
This paper presents preliminary results from a power quality audit conducted at a high-tech campus over last year. Voltage and current were measured at various $R \& D$ buildings. The paper examines the causes and effects of power disturbances that affect computer or any other microprocessor based equipment and analyses the auto-protection capabilities of modern power supplies. The convenience of "enhanced power supply" or "low-cost customer-side" protection solutions is also discussed. Finally it is addressed the role of the Standards on the protection of electronic equipment and the implications for the final costumer.
\end{abstract}

\section{INTRODUCTION.}

With the generalized use of personal computers, microelectronic-based instrumentation and other susceptible devices, the subject of power quality and its relationship to vulnerability of high-tech facilities is becoming an increasing concern not only to the utility companies but, what is more, to the end-customer. Although it is common that public opinion considers utilities as the source of power disturbance problems, they frequently argue that there are circumstances beyond their control. Things like lightning, large switching loads, non-lineal load stresses, inadequate or incorrect wiring and grounding or accidents involving electric lines. These can create problems to sensitive equipment if it is designed to operate within narrow voltage limits, or it does not have adequate ride-through capabilities to filter out fluctuations in the electrical supply [1].

Instrumentation and control operations require high quality and ultra-reliable power in the quantities and time frames that have not been experienced before. It have been estimated that more than $30 \%$ of the power currently being drawn from the utility companies is now heading for sensitive equipment, and increasing [2]. As of today, no standard exists that clearly defines the roles and responsibilities of the energy provider, the high-tech equipment manufacturer, or the high-tech facilities themselves in mitigation of PQ-event-caused losses [3].

Overall, as modern economies move into the $21^{\text {st }}$ century, high-tech users are expected to demand for high SQRA (security, quality, reliability and availability) power supply. In the new and dynamic deregulated electricity environment, this is opening business opportunities for acute energy providers. Reliability is the ability of the power system to supply energy within accepted standards and in the amount desired. Reliability is measured using various indices characterizing frequency, duration, and magnitude of adverse effects on the electric supply. It has been recognized that measures of reliability should include some other power quality issues (such as voltage sag and dip disturbances) that are becoming increasingly significant in the digital age [4]. Contemporary thoughts on this topic are quite differently focused; modern power system reliability relates more to [5]:

- Security. Reducing the vulnerability of the information technology equipment and electricity infrastructures.

- Availability and Reliability. Supporting extreme bus voltage reliability, for example 'five nines' (i.e., 99.9999 availability), or six nines or even higher.

- Quality. Assuring power quality for very large numbers of digital devices

- Self-healing and Redundant. Using distributed energy sources (DERs) to improve reliability

\section{FACILITY OVERVIEW.}

The Rabanales Biotechnology Campus is supplied through a $20 \mathrm{kV}$ feeder emanating from the near substation of "La Lancha". This feeder serve 17 buildings which includes the data centre, the departmental R\&D laboratories, the veterinary hospital, the main library, the lecture hall building, the "Lucano" residence hall, the sports facilities and the train station. Each building has inside one 1000kVA delta-wye transformer which step-down the $20 \mathrm{kV}$ to $230 / 400 \mathrm{~V}$ for the panel boards distributed through the building floors.

While the campus server room is properly served via an UPS, it has been necessary to recognise that the normal electrical conditions outside, in the rest of the campus, are subject to generalised power perturbations. This situation has been the cause of subtle problems such as computer lockups and electronics component wear. Besides, it also has caused more devastating damage as data loss; disk crashes and burnt electronics in almost all of the buildings.

The Rabanales maintenance department required the collaboration of the local utility Endesa-Sevillana, which monitored the service entrance of the campus, concluding that the problems found was not under his responsibility and that the electric service voltage variations were within the $E N$ 50160 standard limits. Thus, was proposed to the authors the 
analysis of power disturbances of the Rabanales campus. Some of the mayor objectives of the power quality study were:

- Correlating the dates presented in the utility report.

- Identifying the power disturbances root causes.

- Characterizing the electromagnetic compatibility (EMC) level of equipments and installation.

- Developing guidelines that help faculty and personnel to understand the power quality concern.

- Providing recommendations for cost-effective solutions.

\section{METHODOLOGY AND RESULTS.}

In order to identify the most likely causes of problems detected, on-site inspections of equipment and installations were conducted over the first week of this study. The power site survey followed well-known approaches [6], [7]. Many power quality problems can be resolved with an appropriate compliment with the latest edition of the "Reglamento electrotécnico para baja tension" (REBT), the Spanish national electrical code. In addition, in the power site visit, we followed the guidelines proposed in [8], [9]. This process included:

- A walk-down of the facility's electrical system to inspect the condition of equipment and becoming familiar with the electrical system.

- Interviewing facility electrical personnel and end-users on failure of equipment.

- Identifying and collecting the electronic equipment that is most sensitive to power disturbances.

- Requesting and reviewing equipment literature and electromagnetic compatibility characteristics.

Even though the installation is not really new, a detailed online diagram of the electrical system was not available. Thus, a complete schematic of the system was developed. In each building the air conditioning system and the elevator are powered via separate branch circuit while in each floor, subpanel serves both the fluorescent lights and the electronic equipments separately. These power circuits are likely to contain more than 120 PCs and terminals, several printers, copiers, facsimile machines, but in addition, chromatographer, spectrometers, ultra violet spectrophotometers and numerous microprocessor-based control and instrumentation devices.

The monitoring device selected was a portable, stand-alone, three-phase power quality analyser [10]. Once the sites were selected, the monitor was connected to the low voltage building entrance and to the different floor sub-panel circuits. Voltage and current values as well as power were logged on the more problematic buildings for periods of one day, one week and one month.

For a typical building entrance, and after a 13 days period measurement, it was evident that the voltage harmonics level was not high. The campus starts activity at 7.00 , this is characterised by the rise in the harmonic level at about this time. As expected the dominant harmonic is the fifth harmonic, this follows the typical daily load pattern. It has its maximum of $2 \%$, at about $16.16(\mathrm{THD}=2.41 \%)$, this is measured the Friday. However, the $6 \%$ compatibility limit for that harmonic order established in EN-50160 standard was not violated. For this period, the $7^{\text {th }}$ harmonic maximum is 0.91 . The most likely cause for the level of the $5^{\text {th }}$ harmonic would be the electronic equipment power supplies. The general rule is that work activity provides, roughly, the largest pollution levels at mid afternoon while during the morning harmonic pollution is lower; since measurement shown were performed in summer, this is likely to be addressed to the incidence of air conditioner actuation between 12 p.m and 19 p.m. and the lack of lighting loads in the morning.

In figures 1 and 2 is shown the current $3^{\text {rd }}, 5^{\text {th }}$ and $7^{\text {th }}$ harmonic levels and the current THD. These harmonic levels are under the UNE-EN-21000-3-4 standard limits, but the THD maximum is $27.54 \%$, which violates the $20 \%$ established limit for the entire installation.

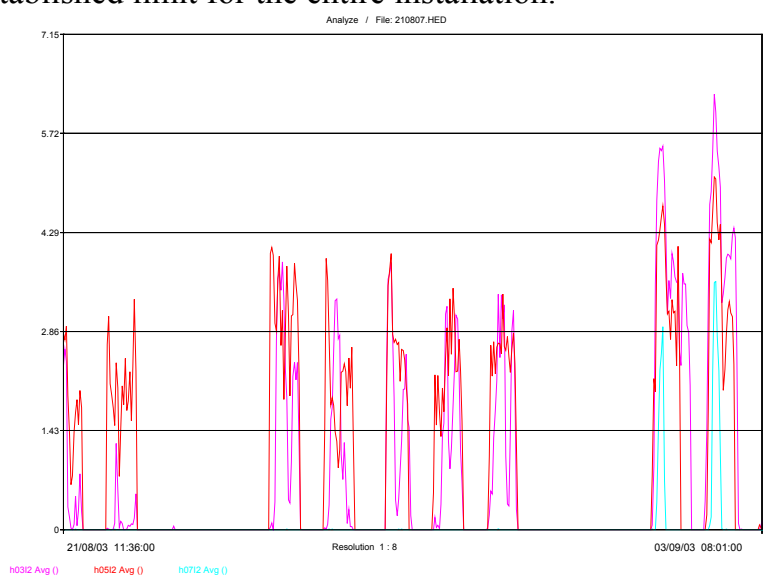

Figure 1. Current $3^{\text {rd }}, 5^{\text {th }}$ and $7^{\text {th }}$ harmonics at $L V$ typical building entrance.

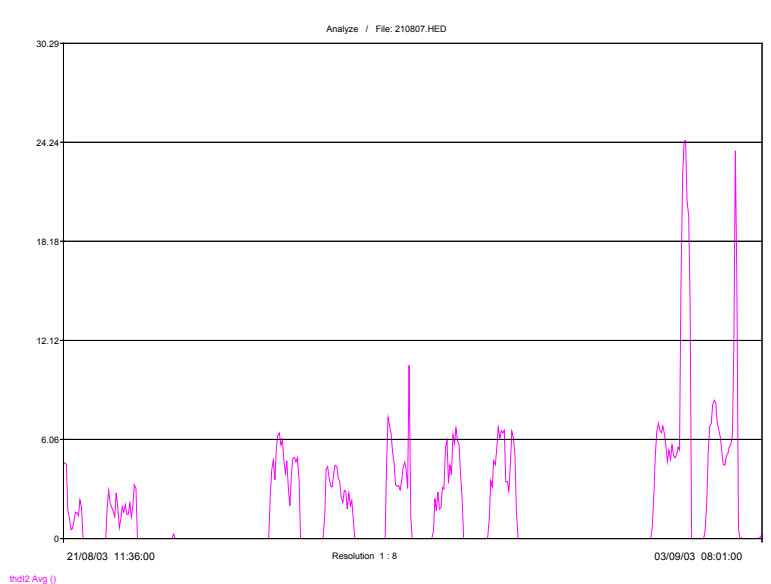

Figure 2. Current THD at LV typical building entrance.

However, a harmonic source can be traced from multiple measurements in the system. The closer one gets to the source, the higher the current distortion level will be. For example, in the organic-chemical laboratory there has been continuous disconnection of the Residual current circuit breakers (RCCB), caused by the impact of spectrometers and chromatographers current. The current THD maximum for the complete laboratory is $58.98 \%$. Meanwhile, the maximum value for the neutral current is $83.51 \%$. The phase current $3^{\text {rd }}$, $5^{\text {th }}$ and $7^{\text {th }}$ harmonic levels have maximum of $20 \%, 11 \%$ and $5 \%$ respectively. The neutral current $3^{\text {rd }}, 5^{\text {th }}, 7^{\text {th }}$ and $9^{\text {th }}$ harmonic levels have maximums of $35 \%, 30 \%, 12 \%$ and $23 \%$ 
respectively. The highest degree of current distortion has been found in the campus server room, where the THD can reach a maximum of $100 \%$; and the phase current $3^{\text {rd }}, 5^{\text {th }}$ and $7^{\text {th }}$ harmonic levels have maximums of $61 \%, 50 \%$ and $38 \%$ respectively.

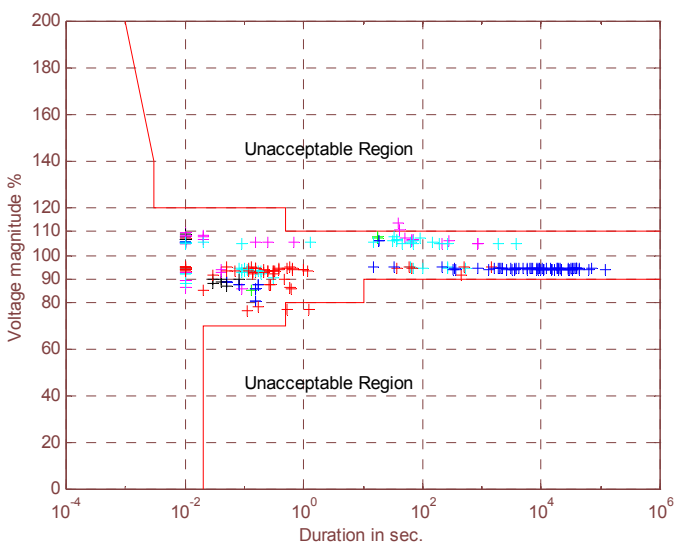

Figure 3. Anomalies detected at LV buildings entrance over the web on ITIC curve.

Figure 3 indicates that, after a monitoring period of one year, disturbances fall within the voltage tolerance envelope of the ITIC curve[11]. Thus, voltages were stable, with a daily fluctuation, and occasionally minor sag and swells, but in most of the cases outside of equipment requirements [12]. Although no voltage outages were recorded, such findings over a relatively short power audit are not conclusive indications of long-term facility or utility continuity of service.

During the monitoring time, and after some recent power disturbance, computer power supplies were damaged (most likely due to transients as shown in figure below) and had to be replaced. Unfortunately our power quality analyser software is not able to identity, classify, or highlight these events. For this purpose we used of a low cost Fluke 43B analyser. Identification of transients involves the manually reviewing all event data and visually scanning all waveforms.

\section{PROPOSED SOLUTIONS.}

Power Quality applications in high-cost diagnostic equipment dictate online double-conversion UPS technology. As opposed to an offline or line-interactive UPS (only recommended for outages), an online system eliminates power quality problems such as sag and surges, including voltage and frequency variations common with standby generator operations.

Even with a uninterruptible power supply (UPS), it takes careful configuration planning to achieve the "five to six nines" of reliability demanded by high-tech facilities. The main element that contributes to system reliability is redundancy. In its basic form, distributed redundancy involves creating two (redundant) UPS system buses and redundant power distributed systems. This eliminates as many single points of failure as practical, all the way up to the load equipment's input terminals. In order to provide "fault tolerance," some method of allowing the load equipment to receive power from both UPS power buses must be provided.
The most advanced online UPS are scalable, with advanced options that are designed for maximum uptime, even those applications where the power simply cannot be interrupted under any circumstances, including routine maintenance. These designs include parallel redundancy, microprocessorcontrolled system, power factor correction rectifier, internal bypass, and multiple monitoring and communication options. To protect against fast power system failures, such as circuit breaker trips or a power system fault, you need a fast switching approach. Static transfer switches (STSs) have been applied to accomplish very fast break-before-make transfers between two ac power sources. It is important that the two $\mathrm{AC}$ power sources be designed as independent as practical to eliminate any common failures.

\section{INSTALLATION RECOMMENDATIONS.}

The general recommendation is to follow well-known ITE installation general guidelines [13] [14], from which the most generally forgotten are:

- Each electronic branch circuit should have individual phase, neutral, and ground conductors. The use of shared neutral conductors as with multi-wire branch circuits is not recommended.

- Connect laser printers and heavy-duty equipment on individual 20 Amp branch circuits. Laser printers and heavy-duty copiers produce high current surges which cause an increase in the neutral to ground voltage. This action can potentially damage other electronic equipment localised on the same branch circuit.

- Install transient voltage surge suppression (TVSS) devices at the service entrance to protect it from utility power problems and lightning strikes.

- At electrical distribution panels, where hard-wired devices help suppress internal voltage transients from spreading to other circuits in your facility.

- At telecommunications and cable local area network circuits, which are extremely vulnerable to voltage transients.

- Install individual TVSS devices at the point of use, where sensitive equipment connects to electrical outlets.

- Specify harmonic cancelling transformers in the design of high-tech facilities.

\section{EMBEDDED SOLUTION FOR LOW-COST EQUIPMENT.}

Voltage sags at the terminals of sensitive equipment are often due to faults occurring at a much higher voltage level. Even though the load current is small compared to the fault current, the changes in load current during and after the fault still strongly influence the voltage at the equipment terminals. It has been discovered that the $85 \%$ of computer malfunctions attributed to poor Power Quality are caused by voltage sag or interruptions of under one second duration [1]. Typical ridethrough capability of power supplies rage from 10 to $30 \mathrm{~ms}$. This time is really too short to be of much help, if switching power supply where modified to one second of ride-through capability, the over kill installation of UPS's can be substituted by a lower-cost power conditioning system [4]. It have been demonstrated that there is a large opportunity to 
embed solutions to voltage-sag problems into advanced electronic tools without requiring large-scale mitigation solutions at the utility or facility-wide level. Basically, an "embedded" solution can range from fairly minor design substitutions for the most sensitive components in a system to major product revisions that incorporate new technologies and possibly require revamping the power scheme inside the equipment.

It is of common sense that equipment that is designed with "built-in" power quality immunity is the best way to achieve system compatibility at lower cost, lower complexity, and higher performance compared to the hindsight practice of retrofitting existing equipment with power-conditioning equipment. However, manufacturers of digital equipment may well underinvested in PQ, primarily because it would increase the cost of their products in highly competitive markets whose customers have not yet shown a willingness to pay extra for better power conditioning.

Broadly speaking, there are three basic options to improve the robustness of DC power supplies in a system [15],[16]:

- Upsize existing power supply. Because the amount of voltage sag ride-through time available from a typical linear or switch-mode power supply is directly related to the loading, power supplies should not be running at or near their maximum capacity. Upsizing by at least two times the nominal load will help the power supply to ride-through voltage sags. This can also be accomplished by adding another identical supply and sharing load with the existing unit.

- Change to three-phase input DC power supplies. Have been demonstrated robust responses from standard linear and switch-mode DC power supplies that utilize a threephase input scheme.

- Change power supplies to use universal input switching power supplies in every location possible. Typically, the universal input type power supply has a voltage range of 90 to $264 \mathrm{Vac}$. When connected phase-to-phase in a $208 \mathrm{Vac}$ system, the power supply can continue to operate for voltage sags as low as 41 percent of nominal (even at full load). This type of supply should be specified for DC-powered instrumentation and $\mathrm{I} / \mathrm{O}$ control voltage. Using this type of power supply for workstation PCs, controllers, and $\mathrm{I} / \mathrm{O}$ will lead to excellent voltage sag ride-through.

Computer manufacturers and their local distributors do no appear to have suitable power quality information readily available. Any information that can be obtained is limited and seems to require a lot of effort to obtain [17]

As a consequence, the almost only source of information is the power supply specification guidelines developed by the owner of the microprocessor system. For example, in highend power supplies from the vendors that INTEL recommends for his microprocessor system [18]. These power supplies are designed to provide protection from higher-thannormal voltages and currents, and provide a limited amount of power-line noise filtering or power factor correction PFC capability.

Most of the inexpensive aftermarket power supplies do not have this sort of protection; concretely, in this study all the computer power supplies damaged belongs to inexpensive clone systems.

In these cases the first recommendation was to replace the damaged power supply by one with the characteristics cited above, and besides to install individual TVSS devices.

\section{CONCLUSION}

The massive penetration of electronically controlled devices and equipment in low voltage distribution networks (the "digital society") could be responsible for the increasing of power quality problems; particularly, we have found that the electronics utilized by most computerized diagnostic instrument, found in biochemical R\&D laboratories, are becoming more sensitive to even minor power perturbation. It have been seen [16] that the level of immunity for some power quality phenomena would be insufficient to adequately protect terminating equipment from the disturbances defined in EN 50160. The 95\% per week basis for assessing most parameters means that actual power quality could result in considerable disruption in equipment performance and yet meet EN 50160.

As stated above, this level of reliability should consider not only service interruptions but also power quality conditions that may cause process disruptions.

The power supply is a component many users ignore when acquiring for an microprocessor-based system, and it is therefore one that some system vendors might choose to skimp on.

After all, a dealer is far more likely to be able to increase the price of a computer by spending money on additional memory or a larger hard drive than by installing a better power supply. Thus, larger consumers, purchasing large numbers of computers and related electronic equipments, should always specify the withstand characteristics of the equipments being purchased.

Finally, for the authors, the European increasing trends in the consumption of power disturbance mitigation equipment reflects the growing consumer implication in this issue, which must be encouraged with the education through the distribution of guidelines and related information. Before considering any further levels of power protection, consumers should know that the power supply in his system could already afford him a substantial amount of protection. What is more, consumer must have a basic knowledge about the power-protection devices available and under what circumstances he should use them.

\section{ACKNOWLEDGMENTS}

The authors would like to thank the Spanish Ministry of Education and Science for funding the project DPI200300878 which supports partially this work.

\section{REFERENCES}

[1]. Gulachenski, E.M.(1995). "The low cost alternative to UPS”. In Electro95 International Proceedings, pp. 97-107.

[2]. Ward, D.J.(2001).Power quality and the security of electricity supply. Proceedings of the IEEE, Vol. 89, Issue: 12 , Dec. 2001, pp:1830 - 1836.

[3]. Pramod Parihar and Edwin Liu (1999). "Power 
Quality Services: Technologies and Strategies for Energy Providers in the Deregulated Market". The Electricity Journal, Vol. 12, nº 9, November 1999, Pp. 79-84

[4]. Robert E. Burns, Scott Potter and Vivian WitkindDavis (2004). After the Lights Went out. The Electricity Journal. Volume 17, Issue 1, JanuaryFebruary 2004, Pages 11-15

[5]. Heydt, G.T.(2002). Grand challenges in electric power engineering: extreme system reliability Power Engineering Society Summer Meeting, 2002 IEEE, vol.3,page(s): 1695 - 1697,21-25 July 2002

[6]. Michaels, K.M. (1997) "Sensible approaches to diagnosing power quality problems". In IEEE Trans. on I. A., vol.33, no 4. pp. $1124-1130$

[7]. Martzloff, F.D. and Gruzs, T.M. (1988) "Power quality site surveys: facts, fiction, and fallacies". IEEE Trans. on I. A., vol.24, no 6, pp. 1005 - 1018

[8]. IEEE recommended practice for powering and grounding sensitive electronic equipment. IEEE Std. 1100-1992.

[9]. IEEE guide for servicing to equipment sensitive to momentary voltage disturbances. IEEE std. 1250, 1995

[10]. GSC-57. HT Instruments. www.htinstruments.com

[11]. Information Technology Industry Council ITIC Curve Application Note.[Online] http://www.itic.org/iss_pol/techdocs/curve.pdf

[12]. Varian 1200 Liquid Chromatographer/Mass Spectrometer Pre-installation Instructions. www.varianinc.com

[13]. Online: http://www.cpccorp.com/tips.htm

[14]. Three Phase Power Source Overloading Caused by Small Computers and Electronic Office Equipment. ITI Information Letter. Online: http://www.itic.org/technical/3phase.htm

[15]. Donmez, Alkan ;Stephens, M. ;Thomas, C.; Banerjee, B. (2001).Embedded Power Quality Solutions For Advanced Machine Tools. Power quality 2001 Conference. http://www.f47testing.com/cncpq/files/PQA2001pape r.pdf

[16]. Stephens, M. ; Soward,J.; Johnson, D; Ammenheuser, J.(2000). Power quality Solutions for Semiconductor Tools, equipment design solutions. Online: $\mathrm{http} / / \mathrm{www}$. powerquality.com

[17]. Annex B2, online: http//www.iee.org.uk/PAB/EMC/core.htm

[18]. Online: http://www.formfactors.org/ 